\title{
Investigation of Mechanical Properties for Reinforced Polyester Composites with Palm Fronds
}

\author{
Ahmad E. Eladawi1,2 (D), A. H. Rajpar1,3 \\ ${ }^{1}$ Jouf University, Sakaka, KSA \\ ${ }^{2}$ Benha University, Benha, Egypt \\ ${ }^{3}$ Quaid-e-Awam University of Engineering, Nawabshah, Pakistan \\ Email: ahmadeladawi@yahoo.com
}

How to cite this paper: Eladawi, A.E. and Rajpar, A.H. (2020) Investigation of Mechanical Properties for Reinforced Polyester Composites with Palm Fronds. Journal of Materials Science and Chemical Engineering, 8, 74-84.

https://doi.org/10.4236/msce.2020.83006

Received: February 12, 2020

Accepted: March 10, 2020

Published: March 13, 2020

Copyright $\odot 2020$ by author(s) and Scientific Research Publishing Inc. This work is licensed under the Creative Commons Attribution International License (CC BY 4.0).

http://creativecommons.org/licenses/by/4.0/

(c) (i) Open Access

\begin{abstract}
Natural fibers have become essential elements to produce composites, which have the renewability, sustainability, low cost and less health hazardous. Natural wastes improved the physical and mechanical properties of polyester-based composites. Reinforced polyester composites with natural fibers are spread widely in recent decades as an alternative to synthetics. This paper deals with effectiveness of palm fronds when they were added to a polyester. Percentage of palm fibers with respect to polyester is considered through present work. A Pin-on-disc tribometer has been used in experimental work under external forces, and the correlations of coefficient of friction have been used to make analysis of the experimental results. Ibertest universal testing machine was used to measure the tensile strength at a crosshead speed of $8 \mathrm{~mm} / \mathrm{min}$. The experimental analysis shows the improvement of properties of the used reinforced polyester, where, the results show that the highest values of coefficient of friction are 1.16667 for $5 \mathrm{~N}$ load and the lowest value is 0.55 for $9 \mathrm{~N}$ load. And the change for load $11 \mathrm{~N}$ is not significant. And also, 7.01 MPa is the highest value for tensile strength with the lowest value of modulus of rigidity 5.84 when the palm frond content is $3 \%$ and the lowest value of tensile test is $4.81 \mathrm{MPa}$ with the highest value of modulus of rigidity 11.9 when $21 \%$ content.
\end{abstract}

\section{Keywords}

Friction Coefficient, Reinforced Polyester Composites, Palm Fronds, Modulus of Rigidity, Tensile Strength

\section{Introduction}

It is a good alternative to the usage of glass fibre as a reinforcement in polyester 
composites which cause bad health effects. It is utilizing as an alternative to other fibre composites. So, it has wide application in new industries which use local crops, wastes. This will make a significant reduction in plastics demand and others.

In the last few decades, interest of researchers deals with the replacement of advanced renewable materials with non-renewable and petroleum-based products [1]. Generally, composite materials possess combination of properties such as stiffness, strength, corrosion resistance, hardness and conductivity which are not possible with the individual component [2]. Light in weight is a huge advantage of natural materials [3]. Low cost, density, sustainable and unlimited availability are other advantages of natural fibers [4]. In recent decades, scientists consider natural fibers which can be used as a potential reinforcement inside polymer composites instead of synthetic fibers [5].

From 1868, the use of natural reinforced polymer composites was a start to fabricate aircraft seats. Through the period 1941 to 1946, it is used to fabricate other aircraft and ship elements as bearings [6]. The composite's properties are affected with distribution, concentration, and orientation of fibers, size, shape and properties of the individual components [1] [5]. Palm fibers are used as composites reinforcement to get excellent properties at a very low cost [7]. Cellulose content of natural fibers makes the mechanical properties are strong and this provides fibers cell walls with high strength and stability [8] [9]. Ishak studies the effect of content of fiber weight fractions on mechanical properties of palm fiber composites [10]. In present work, mechanical properties as coefficient of friction, tensile strength and modulus of elasticity were studied, and, the results showed that properties are increased when fiber percentage is increased.

\section{Experimental Work}

\section{1) Materials}

Frond fiber has the highest cellulose content which is followed by bunch fiber, then ijuk fiber and finally by trunk fiber, whereby these show a good agreement with their tensile strength [11]. Figure 1 illustrates the main content of palm fiber.

To remove dust and sand contents, palm fibers are immersed in water for 5 days. To remove the water inside fiber, palm fibers are taken out and kept in a hot air oven for $60 \mathrm{~min}$ at $150^{\circ} \mathrm{C}$ [12]. Mechanical retting machine was used to extract the fibers to get separated fibers. Figure 2 represents the palm frond fibers.

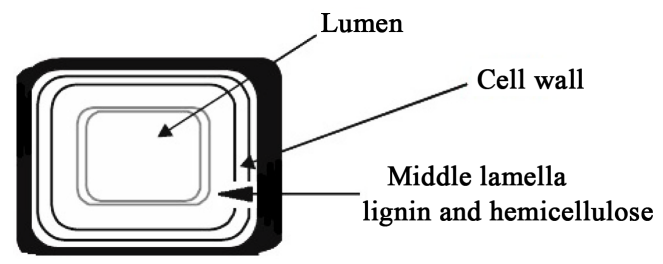

Figure 1. Main palm fiber content. 


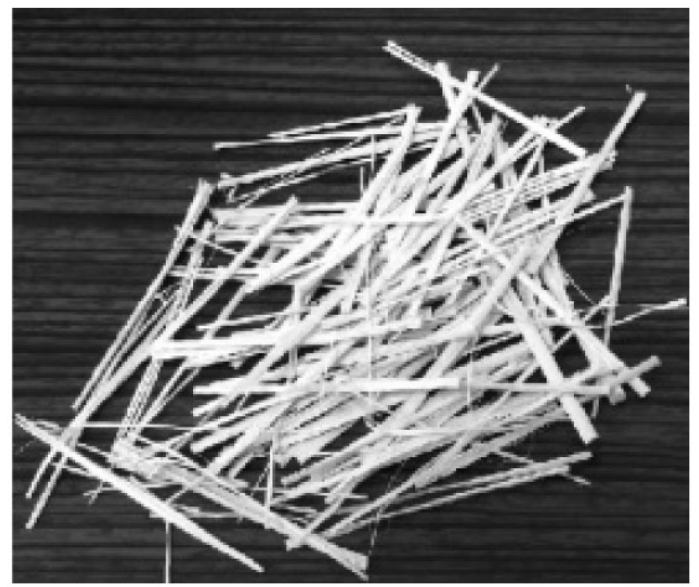

Figure 2. Palm frond fibers.

\section{2) Preparation of Specimens}

Next procedures were taken into consideration to prepare the used specimen. Composites were manufactured by compression molding machine (press capacity $30 \mathrm{~T}$ and $300^{\circ} \mathrm{C}$ ). A steel mold of $400 \mathrm{~mm} \times 400 \mathrm{~mm} \times 15 \mathrm{~mm}$ was used to fabricate the composites. The volume fraction starts from $0 \%$ to $30 \%$ of chopped palm fibre, where this was mixed with polyester with $3 \%$ jumping. Composite mixer was poured inside the die cavity which is closed by hydraulic compression with 3 tons force to get a uniform thickness and to eliminate any porosity. Mold was kept under pressure for 6 hours at room temperature $\left(23^{\circ} \mathrm{C}\right)$. Lastly, specimens were cut to suitable sizes. Finally, specimens were cut into $100 \mathrm{~mm}$ long, $30 \mathrm{~mm}$ width and thickness of $5 \mathrm{~mm}$.

3) Devices

- A pin-on-disc type friction and wear monitoring tribometer (POD) was used to get the coefficient of friction. Under constant conditions, tribometer runs at constant speeds (2000 rpm) and applied normal forces. For tangential force, a load cell is used to measure it. The counterface is a hardened alloy steel disc (EN-31) with surface roughness of $1.6 \mu \mathrm{m}$ and $60-70$ HRC [13]. Four weights (about $0.5,0.7,0.9$ and $1.2 \mathrm{Kg}$ ) are used as external forces $(5,7$, 9 and $12 \mathrm{~N}$ ). Figure 3 represents pin-on-disc tribometer.

- Ibertest universal test machine (with capacity up to $1200 \mathrm{kN}$ ) is used through this work to measure the tensile strength when applying a constant force and various percentage of palm fiber in the composite. Tests were operated at a crosshead speed of $8 \mathrm{~mm} / \mathrm{min}$. Figure 4 represents the used machine.

4) Experiment procedures

- For coefficient of friction: coefficient of friction " $\mu$ " depends on materials nature, surface roughness, sliding speed and pressure of contact [14]. The coefficient of friction was tested in this work according to changes in palm frond percent. 30 specimens were used. While disc was rotated, Pin (specimen) was held and the lever mechanism is used for the applied load [13]. When a normal force was applied on a held specimen over a rotating abrasive 
counterface, a tangential force will be generated at the contact area. This force depends on the friction coefficient and it is monitored on a digital screen. Any experiment with any specimen takes 4 minutes under the used force. Figure 5 illustrates a sketch of pin on the abrasive disc, disc size, wear track due to generated frictions between pin and disc, and directions of normal force $\left(F_{n}\right)$ and tangential force $\left(F_{t}\right)$.

- For tensile test: a tensile strength will be generated with an external force, and it depends on force and cross-section area of the specimen, and modulus of rigidity can be calculated from stress-strain curve slope. For specimen ends, aluminum tabs were glued. The tensile specimen was mounted with the universal machine jaws. The jaws were tightening evenly and firmly to prevent specimen slippage during the test. The operating machine program was adjusted to carry out the test with a cross head speed of $8 \mathrm{~mm} / \mathrm{min}$. Figure 6 illustrates the tensile test.

5) Calculations

- For coefficient of friction: normal force $\left(F_{n}\right)$ which depends upon the mass (m) $\left[F_{n}=\mathrm{m} *\right.$ gravity acceleration], and friction coefficient $(\mu)$ which depends upon friction force $\left(F_{t}\right)$ and $F_{n}\left[\mu=F_{t} / F_{n}\right]$ were calculated. Figure 5 illustrates normal force and the generated friction force.

- For tensile test and modulus of rigidity: the results of tensile strength and modulus of rigidity will be taken from the universal test machine directly.

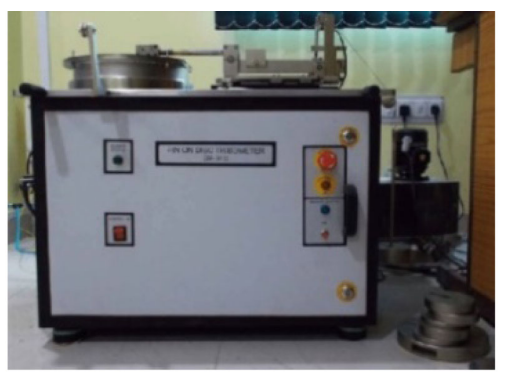

Figure 3. Pin on disc tribometer.

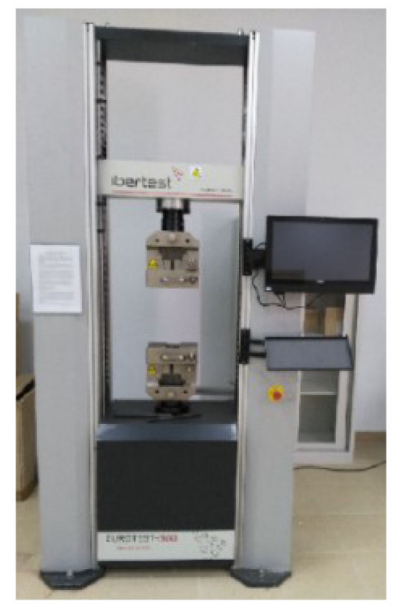

Figure 4. Universal test machine. 


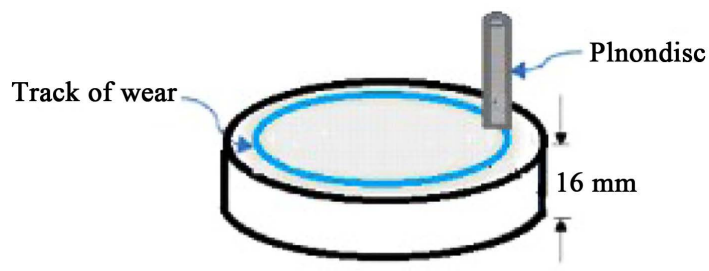

$\mathrm{F}_{\mathrm{n}}$

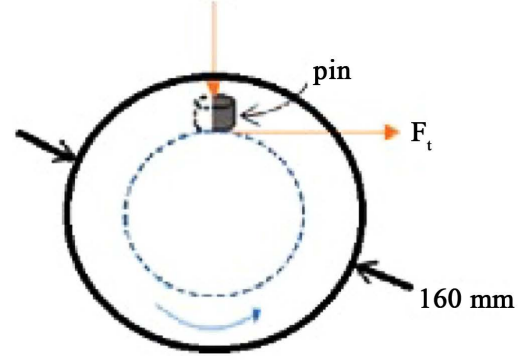

Figure 5. Sketch of pin on disc.

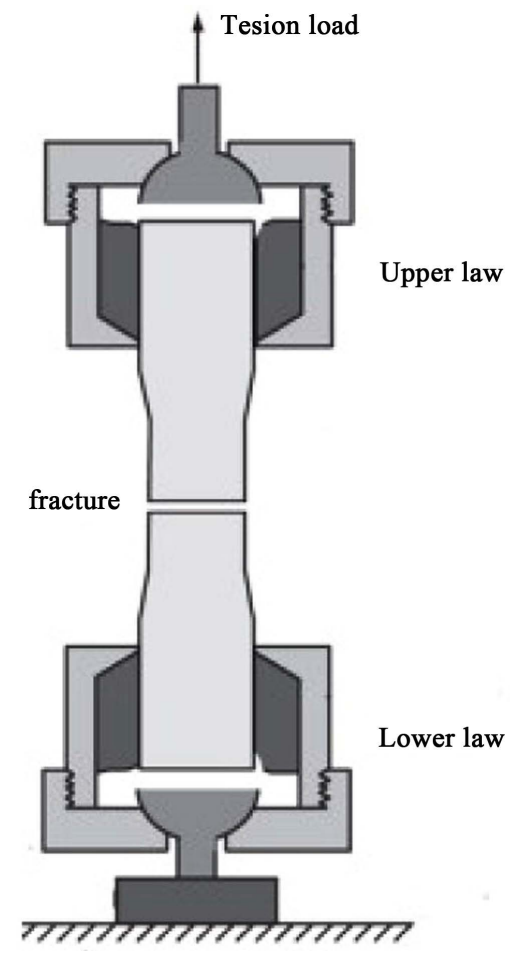

Figure 6. Tension test.

\section{Results and Discussion}

1) For coefficient of friction

Next figures have horizontal axes which represent the percentage of palm fronds and vertical axes which represent the friction coefficient. The figures illustrate the decreasing of coefficient of friction as increasing of load. The friction coefficient of reinforced polyester composites with palm fronds has been examined and it was found that, additional palm fronds enhanced the behavior of the composites. To study the correlation between the friction coefficient and 
percent content of palm fronds, a 2-D chart was drawn between the values of each, and then the correlation coefficient was calculated by Excel. The next figures show that the increasing of volume fraction of palm fronds leads to decreasing of friction coefficient, this is can be explained by the abrasive nature of palm fronds which increases the friction force. So, the value of friction force will be closed to the value of normal force, and this causes a small value of friction coefficient according to its relation.

For $5 \mathrm{~N}$ load: Figure 7 shows positive correlation between friction coefficient and palm fronds percentage $\left(\mathrm{R}^{2}=0.8402\right)$. The figure illustrates the decreasing of friction coefficient due to the increasing of palm fronds.

For $7 \mathrm{~N}$ load: Figure 8 shows positive correlation between friction coefficient and palm fronds percentage $\left(\mathrm{R}^{2}=0.6107\right)$. The figure illustrates the decreasing in friction coefficient is less than the $5 \mathrm{~N}$ case. This is due to the increasing of palm fronds percentage inside the composites, so the friction force will be increased. According to friction coefficient relation, the value of $\mu$ will be more decreased more than $5 \mathrm{~N}$ case.

For $9 \mathrm{~N}$ load: Figure 9 shows positive correlation between friction coefficient and palm fronds percentage $\left(\mathrm{R}^{2}=0.5627\right)$. The figure illustrates the decreasing in friction coefficient is less than the 5 and $7 \mathrm{~N}$ cases. This is due to the more increasing of palm fronds percentage inside the composites, so the friction force will be increased more than 5 and $7 \mathrm{~N}$ cases. According to friction coefficient relation, the value of $\mu$ will be more decreased than 5 and $7 \mathrm{~N}$ cases.

For $11 \mathrm{~N}$ load: Figure 10 shows positive correlation between friction coefficient and palm fronds percentage $\left(R^{2}=0.4995\right)$. The figure illustrates the decreasing in friction coefficient is not significant. This can be interpreted as a result of the high value of friction force which will be closer to the value of normal force. So, the value of $\mu$ in friction coefficient relation will be near to 1 .
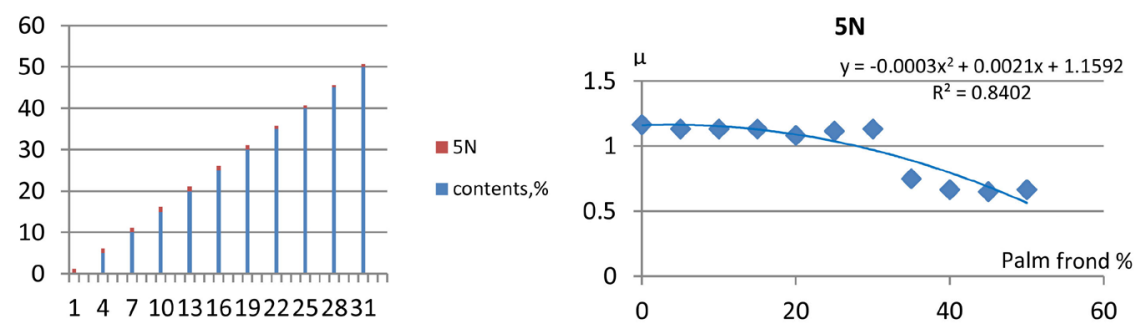

Figure 7. Friction coefficient/content $\%$ for $5 \mathrm{~N}$ load.
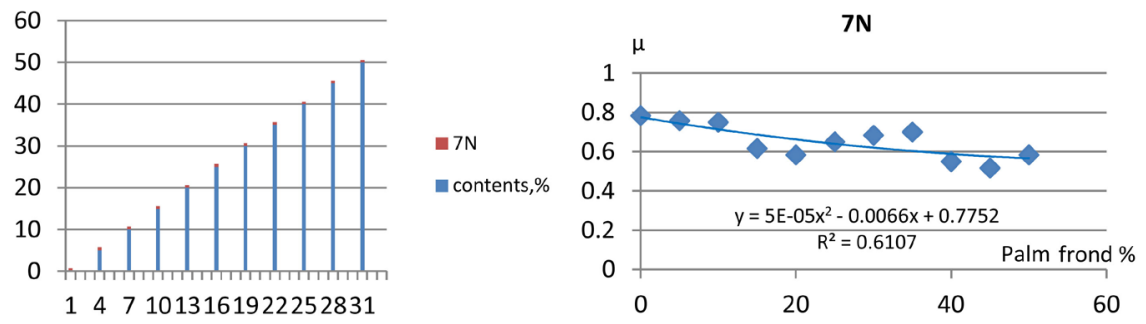

Figure 8. Friction coefficient/content $\%$ for $7 \mathrm{~N}$ load. 
2) For tensile strength

Figure 11 has a horizontal axis which represents the percentage of palm fronds and a vertical axis which represents the tensile strength. To study the correlation between the tensile strength and percent content of palm fronds, a 2-D chart was drawn between the values of each, and then the correlation coefficient was calculated by Excel. The next figure shows that the increasing of volume fraction of palm fronds leads to decreasing of tensile strength, this is can be explained by the abrasive nature of palm fronds which increases the weakness of bonding between its particles, so, the usage of these types of composites requires medium applications with medium properties. The figure shows positive correlation between tensile strength and palm fronds percentage $\left(R^{2}=0.962\right)$.

3) For modulus of rigidity

Figure 12 has a horizontal axis which represents the percentage of palm fronds and a vertical axis which represents the modulus of rigidity. To study the correlation between the modulus of rigidity and percent content of palm fronds, a 2-D chart was drawn between the values of each, and then the correlation coefficient was calculated by Excel.
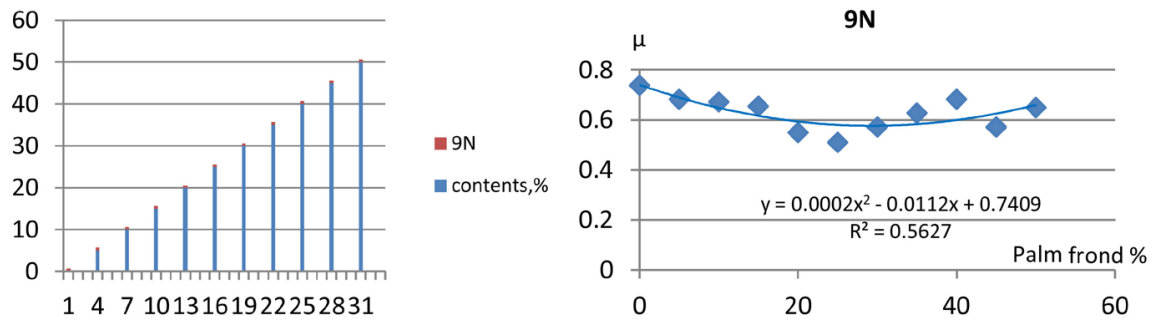

Figure 9. Friction coefficient/content $\%$ for $9 \mathrm{~N}$ load.
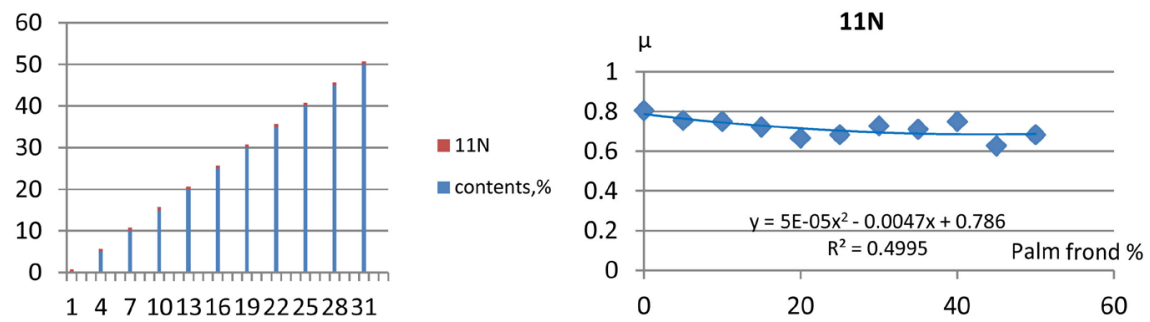

Figure 10. Friction coefficient/content $\%$ for $11 \mathrm{~N}$ load.
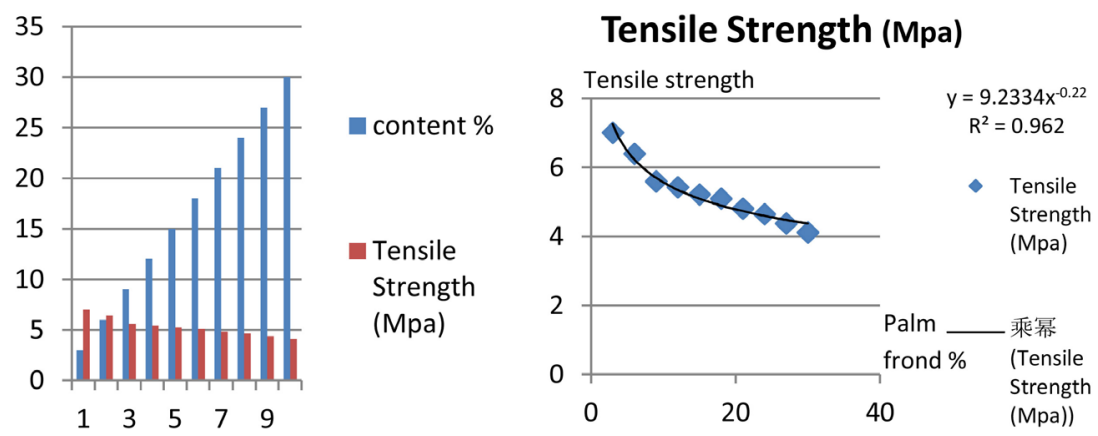

Figure 11. Tensile strength/content $\%$. 


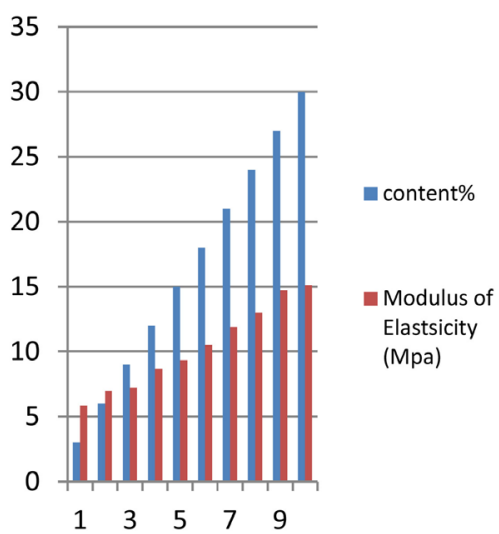

Modulus of Elastsicity

(Mpa)

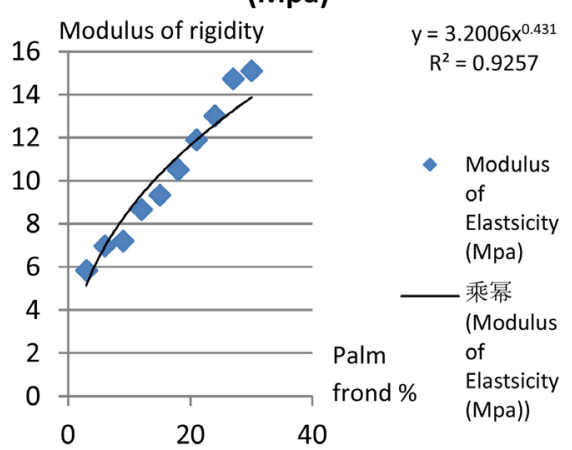

Figure 12. Modulus of rigidity/content $\%$.

The next figure shows that the increasing of volume fraction of palm fronds leads to increasing of modulus of rigidity; this gives an advantage for these types of composite at loading. The figure shows positive correlation between modulus of rigidity and palm fronds percentage $\left(R^{2}=0.9257\right)$.

\section{Conclusion and Recommendations}

This paper represents an experimental investigation of the effect of palm fronds reinforced on composite. Based on the experiments and analysis, next results are extracted:

- Increasing of fraction of volume of palm fronds decreasing friction coefficient because of the abrasive nature of palm fronds which increases the friction force. So, the value of friction force will be closed to the value of normal force, and this decreases the friction coefficient value.

- Increasing of loads is a significant effect where causes decreasing of a coefficient correlation, and increasing of friction force to be very close to normal force, and this decreases the friction coefficient value.

- For $5 \mathrm{~N}$ load, the correlation $(\mathrm{R})=0.9166$. And the friction coefficient is decreased due to the increasing of palm fronds.

- For $7 \mathrm{~N}$ load, the correlation $(\mathrm{R})=0.7815$, this is lesser than $5 \mathrm{~N}$ case. And, the decreasing of friction coefficient is lesser than the $5 \mathrm{~N}$ case.

- For $9 \mathrm{~N}$ load, the correlation $(\mathrm{R})=0.7501$, this value is lesser than 5 and $7 \mathrm{~N}$ cases. And, the decreasing of friction coefficient is lesser than the $5 \mathrm{~N}$ and 7 $\mathrm{N}$ cases.

- For $11 \mathrm{~N}$ load, the correlation $(\mathrm{R})=0.7068$, this value is lesser case in this work. Little decreasing of friction coefficient due to the increasing of palm fronds. But, the decreasing in friction coefficient has not a significant value.

- Increasing of fraction of volume of palm fronds decreasing tensile strength because of the abrasive nature of palm fronds which make the bonding between particles is poor. And, the correlation $(\mathrm{R})=0.9808$.

- Increasing of fraction of volume of palm fronds increasing modulus of rigidity. And, the correlation $(\mathrm{R})=0.9621$. 
The recommendation of the work can be summarized in the nature of applying these results, where these polyester composites can be used when abrasive surfaces are important and in medium tensile strength applications as in some machine elements.

\section{Conflicts of Interest}

The author declares no conflicts of interest regarding the publication of this paper.

\section{References}

[1] Askeland, D.R., Fulay, P.P. and Bhattacharya, D.K. (2013) Essentials of Materials Science and Engineering. 3rd Edition, CL Engineering, New York.

[2] Bagherpour, S. (2012) Fiber Reinforced Polyester Composites. Bagherpour, Licensee InTech, London, 135. http://creativecommons.org/licenses/by/3.0 https://doi.org/10.5772/48697

[3] Muthu Chozha Rajan, B., Senthil Kumar, A., Madhan, V., Paul Pandian, P. and Saravanakumaar, A. (2015) Experimental Investigation and Analysis of Mechanical Properties of Palm Fiber Reinforced Epoxy Composites and Sisal Fiber Reinforced Polyester Composites. Carbon-Science and Technology, 1-15.

[4] Alves, C., Ferrão, P.M.C., Silva, A.J., Reis, L.G., Freitas, M., Rodrigues, L.B. and Alves, D.E. (2010) Ecodesign of Automotive Components Making Use of Natural Jute Fiber Composites. Journal of Cleaner Production, 18, 313-327.

https://doi.org/10.1016/j.jclepro.2009.10.022

[5] Alzebdeh, K.I., Nassar, M.M., Al-Hadhrami, M.A., Al-Aamri, O., Al-Defaai, S. and Al-Shuaily, S. (2017) Characterization of Mechanical Properties of Aligned Date Palm Frond Fibre-Reinforced Low Density Polyethylene. Journal of Engineering Research, 14, 115-123. https://doi.org/10.24200/tjer.vol14iss2pp115-123

[6] Satyanarayana, K.G., Sukumaran, K., Kulkarni, A.G., Pillai, S.G.K. and Rohatgif, P.K. (1986) Fabrication and Properties of Natural Fibre-Reinforced Polyester Composites. Composites, 17, 329-333. https://doi.org/10.1016/0010-4361(86)90750-0

[7] Ishaka, M.R., Sapuana, S.M., Lemana, Z., Rahmand, M.Z.A., Anwarc, U.M.K. and Siregara, J.P. (2013) Sugar Palm (Arenga pinnata): Its Fibres, Polymers and Composites. Carbohydrate Polymers, 91, 699-710.

https://doi.org/10.1016/j.carbpol.2012.07.073

[8] Habibi, Y., El-Zawawy, W., Ibrahim, M.M. and Dufresne, A. (2008) Processing and Characterization of Reinforced Polyethylene Composites Made with Lignocellulosic fibres from Egyptian Agro-Industrial Residues. Composite Science and Technology, 68, 1877-1885. https://doi.org/10.1016/j.compscitech.2008.01.008

[9] Reddy, N. and Yang, Y. (2005) Biofibres from Agricultural by Products for Industrial Applications. Trends in Biotechnology, 23, 22-27. https://doi.org/10.1016/j.tibtech.2004.11.002

[10] Ishak, M.R. (2009) Mechanical Properties of Treated and Untreated Woven Suga Palm Fibre-Reinforced Unsaturated Polyester Composites. University Putra Malaysia, Malaysia.

[11] Siregar, J.P. (2005) Tensile and Flexural Properties of Arenga Pinnata Filament (Ijuk Filament) Reinforced Epoxy Composites. University Putra Malaysia, Malaysia.

[12] Shinji, O. (2008) Mechanical Properties of Kenaf Fibres and Kenef/PLA Compo- 
sites. Mechanics of Materials, 40, 446-452.

https://doi.org/10.1016/j.mechmat.2007.10.006

[13] Aherwar, A., Singh, A., Patnaik, A. and Unune, D. (2018) Selection of Molybdenum Filled Hip Implant Material Using Grey Relational Analysi Method. In: Handbook of Research on Emergent Applications of Optimization Algorithms, IGI Global, New York.

[14] Arnoux, J.J., Sutter, G., List, G. and Molinari, A. (2011) Friction Experiments for Dynamical Coefficient Measurement. Advances in Tribology, 2011, Article ID: 613581. https://doi.org/10.1155/2011/613581 


\section{Appendix A}

Table A1 illustrates friction coefficient values versus palm fronds content \%.

Table A1. Friction coefficient values versus palm frond contents $\%$.

\begin{tabular}{cccccccc}
\hline \multicolumn{7}{c}{ friction coefficient/content \% } \\
\hline Contents \% & $5 \mathrm{~N}$ & Contents $\%$ & $7 \mathrm{~N}$ & contents $\%$ & $9 \mathrm{~N}$ & contents \% & $11 \mathrm{~N}$ \\
\hline 0 & 1.16667 & 0 & 0.78333 & 0 & 0.73889 & 0 & 0.80556 \\
3 & 1.13333 & 3 & 0.75833 & 3 & 0.68333 & 3 & 0.75556 \\
6 & 1.13333 & 6 & 0.75 & 6 & 0.67222 & 6 & 0.75 \\
9 & 1.13333 & 9 & 0.61667 & 9 & 0.65556 & 9 & 0.72222 \\
12 & 1.08333 & 12 & 0.58333 & 12 & 0.55 & 12 & 0.66667 \\
15 & 1.11667 & 15 & 0.65 & 15 & 0.51111 & 15 & 0.68333 \\
18 & 1.13333 & 18 & 0.68333 & 18 & 0.57222 & 18 & 0.72778 \\
21 & 0.75 & 21 & 0.7 & 21 & 0.62778 & 21 & 0.71111 \\
24 & 0.66667 & 24 & 0.55 & 24 & 0.68333 & 24 & 0.75 \\
27 & 0.65 & 27 & 0.51667 & 27 & 0.57222 & 27 & 0.62778 \\
\hline & 0.66667 & 30 & 0.58333 & 30 & 0.65 & 30 & 0.68333 \\
\hline
\end{tabular}

\section{Appendix B}

Table B1 illustrates tensile strength and modulus of rigidity values versus palm fronds content $\%$.

Table B1. Tensile strength and modulus of rigidity values versus palm frond contents $\%$.

\begin{tabular}{ccc}
\hline Contents \% & Tensile Strength (Mpa) & Modulus of Rigidity (Mpa) \\
\hline $\mathbf{3}$ & 7.01 & 5.84 \\
6 & 6.4 & 6.98 \\
9 & 5.6 & 7.21 \\
12 & 5.43 & 8.67 \\
15 & 5.22 & 9.34 \\
18 & 5.1 & 10.52 \\
21 & 4.81 & 11.9 \\
\hline
\end{tabular}

